\title{
Um Aspecto da Política Econômica do "Milagre Brasileiro": A Política de Mercado de Capitais e a Bolha Especulativa 1969-1971
}

\author{
- José PedRo MACARINI*
}

\begin{abstract}
RESUMO
Este artigo busca contribuir para a literatura sobre a política de mercado de capitais desenvolvida pelo regime militar ocupando-se de um capítulo que permaneceu inexplorado, qual seja, as principais medidas e seus resultados observados no período 1968-1973. Nesses anos ocorreu um vigoroso ciclo de crescimento e, em 1969-197I, um exuberante processo especulativo na Bolsa (em uma fase inicial interpretado pelas autoridades como sinal de êxito da política econômica do regime). O fim da bolha especulativa foi seguido de uma prolongada estagnação da Bolsa, não obstante reiteradas tentativas da política econômica de revitalizar o mercado de capitais.
\end{abstract}

\section{Palavras-CHave}

Brasil - ditadura militar, Brasil - política econômica

\section{ABSTRACT}

This article aims to contribute to the literature on the Brazilian capital market policy implemented during the military dictatorship, examining an unexplored chapter, that related to its main aspects and results observed during the so-called Brazilian "miracle" (1968-1973). During those years an impressive growth cycle occurred as well as an exuberant bubble in the stock market (in its initial phase interpreted by the authorities as a clear signal of the correctness and success of the regime's economic policy). The end of the bubble led to a prolonged stagnation in the stock market, which never resumed during the 70 s despite the many successive efforts by the economic policy to revitalize it.

\section{KEYWORDS}

Brazil - military dictatorship, Brazil - economic policy

\section{JEL Classification}

\section{E650}

\footnotetext{
* Professor Assistente Doutor do Instituto de Economia da UNICAMP - Campinas - SP. Endereço para contato: Rua Fernandes Sardinha, 76. Vila Bela - São Paulo - SP - CEP: 03 I47-020. E-mail: macarini@eco.unicamp.bir.

(Recebido em setembro de 2006. Aceito para publicação em junho de 2007).
} 


\section{INTRODUÇÃO}

A economia brasileira configura um caso exemplar de industrialização tardia e desenvolvimento na periferia do sistema capitalista internacional. Após um longo período de intenso desenvolvimento, o Brasil experimentou uma complexa crise econômica no início da década de 60 . No terreno da política, combinando-se com outras determinantes (como a influência do cenário internacional, marcado pelo acirramento do confronto geopolítico entre os Estados Unidos e a União Soviética), a conjuntura de crise culminou no golpe militar de 1964, inaugurando um regime que perduraria por duas décadas. A crise econômica prosseguiu durante o triênio inicial do novo regime, período assinalado por ampla ação da política econômica, responsável por grandes mudanças no quadro geral da economia brasileira - ainda que a sua configuração estrutural e a dinâmica de expansão tenham sido, no essencial, preservadas, reproduzindo um padrão de acumulação cuja emergência deve ser localizada no Plano de Metas do governo JK. A partir de 1967-1968, teve início um vigoroso ciclo expansivo que, desde o começo do governo Médici (outubro de 1969 a março de 1974), a ação retórica do regime transformou no "milagre brasileiro". Nesse período, o fascínio suscitado pelo crescimento acelerado exacerbou as ambiçôes manifestadas pelo regime, o que se sintetizou no projeto Brasil Grande Potência. O governo seguinte, do presidente Geisel, deu pleno curso a esse projeto, embora tenha implementado uma mudança substantiva na orientação da política econômica.

O objetivo deste artigo é examinar um aspecto específico da política econômica da ditadura, qual seja, a política de mercado de capitais. Ocupando um papel de relevo no âmbito das reformas avançadas durante o governo Castello Branco, essa política experimentou uma seqüência de capítulos adicionais nos governos militares seguintes. A literatura existente produziu magníficos estudos da reforma e do capítulo exibido durante o II PND (Plano Nacional de Desenvolvimento) de Geisel. Contudo, o interregno entre esses dois momentos - período em que se nota uma mudança de perspectiva na condução da política de mercado de capitais - permaneceu inexplorado. Os acontecimentos associados a esse período possuíam um interesse intrínseco. Além disso, ensejaram uma caracterização mais adequada e completa do "milagre brasileiro", influenciando o comportamento subseqüente do mercado de capitais e as correspondentes ações da política econômica. Nesse sentido, busca-se aqui adicionar à literatura sobre o tema uma tentativa de revisão dos principais aspectos da política de mercado de capitais e seus resultados no período 1968-1973.

O artigo é composto por cinco seções. Na seção 1 faz-se uma breve recapitulação da reforma do mercado de capitais e apresentam-se os objetivos almejados. Na seção 2, reconstitui-se a condução da política de mercado de capitais no período imediatamente após o AI-5 de dezembro de 1968. Procura-se mostrar que, ao lado da faceta de 
continuidade revelada por essa linha de ação da política econômica, ocorreu uma mudança de perspectiva quando se tentou apressar a consolidação do mercado de capitais incentivando mais firmemente as transações em Bolsa. Os resultados dessa política, uma bolha especulativa desenvolvida em duas etapas, são examinados nas seçôes 2 e 3. A seção 4 mostra como, após o melancólico colapso da bolha, a política de mercado de capitais prosseguiu sendo acionada com perseverança, sem lograr quaisquer resultados significativos. A seção final, a título conclusivo e com espírito crítico, faz breves considerações sugeridas pela seqüência de episódios da década de 70 .

\section{AS REFORMAS INSTITUCIONAIS DE CAMPOS - BULHÕES E O MERCA- DO DE AÇOEES}

Durante o governo Castello Branco, a preocupação central da política econômica foi o combate à inflação, em franca aceleração desde 1959. O PAEG (Plano de Ação Econômica do Governo) sintetizou o diagnóstico e as diretrizes da política de estabilização que, não sem contradições em sua execução, foram efetivamente perseguidas no triênio 1964-1966. Esperava-se que o sucesso na busca da estabilidade fosse acompanhado pela retomada do desenvolvimento a taxas históricas. Como se sabe, os resultados imediatos do PAEG foram frustrantes e levaram a uma mudança de curso da política econômica com Delfim Netto em 1967. ${ }^{1}$

Em paralelo à política de estabilização, um conjunto amplo de reformas no terreno institucional foi implementado. O seu sucesso foi desigual, assim como a sua importância na sustentação do ciclo expansivo observado a partir de 1967; ademais, os desdobramentos subseqüentes à fase de introdução mostraram-se bastante variados (em alguns casos até mesmo inesperados, tal o distanciamento em relação ao projeto reformista original - o caso conspícuo, aqui, foi a reforma financeira). A ação reformista contemplou em um dos seus capítulos o mercado de ações. ${ }^{2}$

Este, embora não fosse uma criatura recente, jamais desfrutara de um desenvolvimento significativo. No período em questão, diversos fatores contribuíam em maior ou menor medida para impedir o seu desabrochar: o ambiente cronicamente inflacionário (responsável pela concentração das transações em poucas ações), a má organização das Bolsas (propiciando a manipulação), o monopólio dos corretores públicos, a forma de atuação das sociedades de investimento (marcada por "certas práticas predatórias"), uma legislação inadequada (por não resguardar os direitos dos acionistas minoritários), uma tributação penalizadora do mercado (com impostos excessivos sobre os rendimentos). O diagnóstico oficial via nas "excessivas flutuações das cotações de

l Para um exame detalhado, ver Fishlow (1974), Resende (1982) e Sochaczewski (1980).

2 Sobre as reformas, ver Silva (1980) e Almeida (1984). 
Bolsa", sub-produto da incidência de tais fatores, o pecado original a ser devidamente purgado. A reforma do mercado de capitais (Lei n ${ }^{\circ} 4.728$, de 1965) buscou atacar aquele conjunto de problemas - modernizando as Bolsas, extinguindo o monopólio dos corretores públicos etc. - e criar um sistema de distribuição de valores mobiliários, composto de corretoras e distribuidoras (com atuação no "varejo") e dos bancos de investimento (dotados da atribuição de agentes "atacadistas" do mercado). ${ }^{3}$

A expectativa dos responsáveis pela reforma era a de, criando as necessárias condiçôes institucionais para tal, lograr mobilizar um fluxo expressivo de poupança destinado à capitalização empresarial. Segundo Bulhões Pedreira:

"... o desenvolvimento do mercado dependeria da execução da lei, de se criar o sistema, buscando investidores, expandindo a poupança, deslocando poupança dos imóveis e de outras formas de aplicação.” - em suma, "...reconhecia-se que era necessário estimular a formação de poupança”. ${ }^{4}$

Uma vez confirmada essa expectativa, estaria aberto o caminho para um firme crescimento das empresas - tanto o fortalecimento da grande empresa já existente, agora desembaraçada da excessiva dependência de crédito (um fator limitante de sua expansão), quanto o surgimento de novas grandes empresas através de seu paulatino crescimento. $\mathrm{Na}$ avaliação taxativa de Bulhões Pedreira:

“... o problema é que se você não tiver um mercado de ações, não há possibilidade de uma empresa crescer de pequena para média, de média para grande. Chega um ponto que não cresce mais. Na base de empréstimo e de auto-financiamento não dá.”

Assim seria possível evitar uma situação potencialmente perigosa: "Se não existirem mecanismos privados de capitalização em larga escala a empresa só pode nascer grande se for estrangeira ou estatal. É o que observamos hoje”. 5

3 Essa descrição foi feita, a posteriori, por um dos arquitetos da reforma, o jurista Bulhões Pedreira. Ver Almeida (1984, p. 26).

4 Ver Almeida (1984, p. 35-36).

5 Ver Almeida (1984, p. 30-31). Convém notar que a preocupação com o fortalecimento da empresa privada nacional tendeu a crescer ao longo de sucessivos governos militares, tornando-se uma diretiva central da política econômica durante o II PND. Ver a respeito Lessa (1998). Por outro lado, o atrativo exercido pela tese da "democratização do capital" também terá tido o seu papel na gestação da reforma - conforme se depreende da "confissão" de Roberto Teixeira da Costa, um entusiasta do mercado de ações: "Confesso que faço parte da legião que, romanticamente, entendia que, independentemente do esforço institucional para se criar o mercado, para se ter uma sociedade realmente capitalista precisava de (sic) baver uma participação individual no mercado. Conhecendo, recebendo dividendos da empresa, a pessoa passa a acreditar no sistema de uma forma melhor que, por exemplo, depositando em caderneta de poupança." Ver Almeida (1984, p. 37). 
Essa linha de argumentação deve ser sublinhada, dada a sua importância no discurso dos próceres (e entusiastas) da reforma do mercado de capitais. O insuficiente desenvolvimento do sistema financeiro (restrito a operações de curto prazo) e do mercado de capitais era visto como uma séria limitação ao crescimento, dado que, nesse quadro, o setor produtivo ficava desprovido de uma poderosa alavanca do processo de acumulação (o crédito de longo prazo). E, não menos importante: a estrutura conformada desde o pós-guerra - caracterizada por uma crônica dependência do empresariado industrial diante do sistema financeiro para a viabilização dos níveis correntes de produção - criava uma situação francamente adversa à expansão das empresas, sufocadas por passivos predominantemente de curto prazo, de difícil administração, exercendo um contínuo efeito corrosivo sobre as massas de lucro. Enquanto a grande empresa se via tolhida em seu impulso à expansão, para as pequenas e médias empresas o crescimento jamais passaria de um sonho. Assim, liberar o potencial de crescimento da economia - e com uma decisiva presença da empresa privada nacional - implicaria suprimir aquele vício de juventude do capitalismo brasileiro, desenvolvendo um sistema financeiro capaz de operar a longo prazo e um mercado de capitais vigoroso. ${ }^{6}$

Originalmente, a criação do banco de investimento foi a inovação de maior alcance, pois, em tese, ele deveria cumprir aqueles dois objetivos. De fato, ao agente "atacadista” era reservado um papel fundamental na expansão futura do mercado de ações. Como o mercado era apenas incipiente e o ambiente inflacionário ainda prosseguiria (dado o tratamento "gradualista” em curso), não se vislumbrava tão cedo uma presença ativa do pequeno poupador. Isso conferia à nova instituição o papel de verdadeiro agente desbravador do almejado mercado de capitais. Atuando agressivamente em operações de underwriting (no "atacado") estimularia o lançamento de ações por parte das empresas candidatas a democratizar o seu capital (deflagrando, pois, um benfazejo processo de capitalização empresarial); posteriormente, e de forma gradual, repassaria ao "varejo" a sua carteira de ações e contribuiria para a atração do investidor individual, alargando o mercado. ${ }^{7}$

Havia, contudo, uma firme crença na existência de um grande potencial de poupança, que ou não era realizado ou era desviado para aplicações alternativas (imóveis ou títulos a juros). O crescimento do mercado de ações no decurso do tempo deveria refletir o êxito alcançado na captura de parte dessa poupança dos investidores individuais. Nesse sentido, atuaria uma política de incentivo à formação de poupança pessoal, preferencialmente voltada à compra de ações. A própria lei 4.728 inaugurou essa política ao fixar diversas vantagens fiscais ao investidor em ações: dedução da renda bruta, para cálculo do imposto de renda devido, de montantes variados da aplicação feita e

6 Ver especialmente o depoimento de Dênio Nogueira, ex-presidente do Banco Central de abril de 1965 a março de 1967, reproduzido em Wanderley e Pimentel (1970).

7 Ver os depoimentos de Bulhões Pedreira, Dênio Nogueira e Garrido Torres, reproduzidos em Wanderley e Pimentel (1970). Ver, também, Almeida (1984, p. 26). 
dos dividendos e bonificações em dinheiro recebidos; isenção do imposto de renda na fonte sobre os rendimentos de açôes nominativas; alíquota diferenciada do imposto de renda na fonte sobre rendimentos de açóes ao portador $(25 \%$ no caso de sociedade de capital aberto e $40 \%$ no caso de sociedade de capital fechado). Já em 1967, essa política ganhava impulso com o Decreto-Lei $n^{\circ} 157$, permitindo canalizar parte do imposto de renda devido para o mercado de ações através de fundos de investimento - originalmente restritos à compra de ações novas (mercado primário). Note-se a estrita vinculação dessa medida ao objetivo de melhorar a capitalização das empresas; em paralelo, esperava-se, contribuiria para a educação do poupador atraindo a sua atenção para o investimento em ações. ${ }^{8}$

As empresas também foram incentivadas a abrir o seu capital - assim modernizandose e, em tese, ensejando um leque mais atrativo de opções ao investidor individual. Talvez a vantagem mais estimulante concedida com esse propósito tenha sido a isenção do imposto de renda adicional de $5 \%$ incidente sobre a distribuição de lucros. O processo de abertura de capital seria regulamentado pelo Banco Central já em 1966 (através das resoluções 16 e 26) ao estabelecer as condições para a concessão do certificado de capital aberto (CCA). Por prazo indeterminado, no caso das sociedades anônimas que alcançassem um "alto grau de negociabilidade" de suas ações (um conceito indefinido); temporário (um ou dois exercícios), no caso de a difusão do capital alcançar pelo menos $15 \%$ do capital da sociedade anônima. ${ }^{9}$

\section{VICISSITUDES DA POLÍTICA DE MERCADO DE CAPITAIS: GESTAÇÃO DA BOLHA ESPECULATIVA NO MERCADO DE AÇÕES (1968 - 1969)}

Não obstante a reforma do mercado de capitais e o contínuo apoio oficial, até o final de 1968 o mercado de ações se mantinha sumamente exíguo. Ademais, alguns desdobramentos observados na área financeira conflitavam com as previsões originais das reformas de Campos-Bulhões: proliferação de bancos de investimento (previu-se seis ou sete, surgiram mais de 20) e fracasso no cumprimento das funções que lhes deram origem; permanência de elevados custos operacionais no setor; acelerada acumulação financeira e intensificação da concorrência na ponta da captação de recursos gerando um ambiente de altas taxas de juros. A inflação, embora substancialmente reduzida,

8 Uma interessante questão, aqui tangenciada, diz respeito à real dimensão da poupança familiar no processo mais geral de formação de poupança no capitalismo. Os entusiastas do mercado de ações exageram a sua importância. Ver o debate entre M.C.Tavares, R. T. Costa e Bulhôes Pedreira, reproduzido em Almeida (1984, p. 33-38).

9 Ao não distinguir entre ações ordinárias e preferenciais e ao facultar o CCA definitivo sem a contrapartida de progressivo aumento do grau de difusão, a regulamentação do Banco Central parecia pouco preocupada com o objetivo da "democratização do capital". Para um exame detalhado da legislação, ver Conjuntura Econômica, nov. 1970, set. 1972 e set. 1973. 
ainda se afigurava excessivamente alta, enquanto o crescimento econômico (em pleno curso) não era visto como resultante de um processo sustentado - a tal ponto a conjuntura era assim percebida que a tônica da política econômica, definida logo após a edição do AI-5, foi comunicada oficialmente como um obrigatório "ataque mortal" à inflação, pré-condição do desenvolvimento sustentado (à PAEG). Os tradicionais problemas do empresariado nacional manifestavam-se de forma talvez até mais explícita, dado o debilitamento experimentado ao longo da crise, os resultados ainda precários das reformas e a permanência dos juros altos. Nesse contexto, a política de mercado de capitais inaugurada em 1964 exibe um segundo capítulo. Com efeito, em face dos decepcionantes resultados colhidos até então, a política econômica parece ter tentado apressar a consolidação do mercado secundário - como se julgasse a ativação das operações em Bolsa uma pré-condição para o êxito na construção do mercado de capitais (ou, no mínimo, um atalho, ainda que perigoso: o incerto avatar do poupador familiar de especulador em investidor). ${ }^{10}$

É assim que uma série de medidas de incentivo à formação de poupança pessoal voluntária e à democratização do capital são implementadas. A nova regulamentação do processo de abertura de capital foi mais coerente com aquele objetivo ao estabelecer como requisito para a obtenção do CCA uma distribuição inicial mínima de $20 \%$ do capital em ações ordinárias (até então a distribuição podia ser na forma de ações preferenciais, sem direito a voto); sua validade seria temporária (dois anos), exigindo-se para sua renovação uma ampliação de pelo menos 10\% no grau de difusão - o CCA definitivo somente seria outorgado quando o grau de difusão atingisse 49\% (Resolução no106, de 11.12.1968). A resposta do setor empresarial sem dúvida ocorreu, mas sem chegar a sinalizar alguma mudança fundamental de comportamento. ${ }^{11}$

Em paralelo, ampliaram-se notavelmente os incentivos à compra de ações. Cabe destacar:

- redução do imposto de renda sobre dividendos: de $40 \%$ para $25 \%$ no caso das sociedades de capital não aberto; de $25 \%$ para $15 \%$ (ações ao portador) e isenção (ações nominativas) no caso das sociedades de capital aberto (Decretos-Lei n⿳401, de 30.12.1968, e no427, de 8.01.1969);

10 Ver a respeito as agudas observações de Keynes (1983, cap. 12).

11 O número de sociedades de capital aberto evoluiu de 289 em 1968 para 296 em 1969 (80 novos certificados contra 73 cancelamentos); em 1970-1971 atingiria cerca de 400 e 493 respectivamente, refletindo a conjuntura febril do mercado. Mas o fato de novas chamadas de capital não serem freqüentes permite especular que o propósito de muitas empresas participantes do processo era muito mais o de distribuir lucros acumulados com isenção do imposto de renda devido (5\%), ou, ainda, usufruir dos atrativos ágios cobrados na emissão primária (muitas vezes acima de $100 \%$ no auge da bolha especulativa), tratados como rendimento não tributável pela Lei n ${ }^{\circ} 4.728$. 
- mudança na sistemática do Decreto-Lei no 157 : elevação de $10 \%$ para $12 \%$ do benefício concedido às pessoas físicas (em contrapartida, redução de $5 \%$ para $3 \%$ em 1969 e 1\% em 1970, no caso das pessoas jurídicas); permissão para que um terço dos recursos dos fundos de investimento fossem aplicados na compra de ações transacionadas em Bolsa (Decreto-Lei nº403, de 30.12.1968);

- isenção de imposto de renda sobre a incorporação de reservas ao capital social, inicialmente com prazo de validade até 30-06-69 (Decreto-Lei nº401), depois seguidamente prorrogado; (à época muitas empresas cotadas em Bolsa dispunham de vultosas reservas, cuja incorporação reverteria em bonificações aos seus acionistas);

- diminuição da rentabilidade dos títulos de renda fixa: incidência de imposto de renda na fonte, alíquotas diferenciadas (variando de 10\% para títulos de 180 dias a $4 \%$ para os de prazo igual ou superior a 720 dias), sucessivas reduções das taxas de juros nominais administradas pelo Banco Central (iniciadas com a Resolução no115, de 1969).

Coincidentemente, observa-se no período um cerco a algumas atividades, de cunho marcadamente especulativo, à margem do sistema financeiro institucionalizado. Tal foi o caso do ativo mercado paralelo de notas promissórias e letras de câmbio "particulares", que se buscou reprimir a partir do Decreto-Lei no 427 , de 8-1-69; e igualmente do mercado de câmbio negro, desestimulado com a introdução do regime de minidesvalorizações cambiais (em agosto de 1968). ${ }^{12}$ É plausível supor que parte desses recursos foi direcionada ao mercado de ações, uma atrativa alternativa de valorização francamente apoiada pela política econômica.

O ano de 1969 foi um divisor de águas na evolução do mercado de ações. Até então o seu desempenho era inexpressivo e não exibia nenhuma tendência clara de expansão. Nesse ano, porém, o volume de transações (Bolsa de Valores do Rio de Janeiro e de São Paulo, somadas) simplesmente multiplicou-se por cinco, em valores reais, atingindo uma cifra anual várias vezes superior ao recorde anterior (verificado em 1963). A forte ampliação do volume de negócios refletiu-se numa intensa valorização dos títulos: o IBV (Índice da Bolsa de Valores) do Rio de Janeiro acumulou uma espetacular valorização de $484 \%$ em relação a 1968, enquanto o índice Bovespa multiplicou-se por 2,2 (chegando a 2,7 entre janeiro e agosto, pico do movimento altista). Sem dúvida um repentino boom colhido na esteira da nova política econômica suscitada pelo

12 Uma estimativa feita em 1970, após a obrigatoriedade de registro estabelecida pelo Decreto-Lei nº427, apontava uma soma de recursos equivalente a $50 \%$ do valor global dos títulos em circulação no sistema financeiro de emissão privada. Ver Carta Mensal APEC 12/06/70, p. 160-161. Sobre a especulação cambial em 1968, inclusive dificultando a execução da política monetária, ver os comentários de Ernane Galveas, então presidente do Banco Central, na Revista de Finanças Públicas, abr. 1969, p. 26. 
AI-5 e que tinha no fomento do mercado de capitais um de seus pilares. O objetivo perseguido desde a reforma parecia despontar no horizonte.

Embora a recuperação da economia já estivesse em curso - e em 1968 a taxa de crescimento industrial tenha sido exuberante - convém não perder de vista que o "milagre" brasileiro ainda não tinha começado e a política econômica, diferentemente do observado em 1967-1968, voltava a ser dominada pela forte preocupação com a inflação (a ponto de permitir identificar nesse momento uma nova inflexão de rumo). Nesse sentido, inexiste - no ano de 1969 - qualquer vinculação mais significativa entre o dinamismo do mercado de ações e o ciclo expansivo (e as expectativas otimistas que enseja). Certamente, a política econômica deflagrou o processo: persistentes expectativas de um amplo movimento de incorporação de reservas (fomentado pelo DecretoLei $\mathrm{n}^{\circ} 401$ ) contribuíram para desatar a alta das cotações (intensificadas pelas práticas do mercado, onde boatos valem tanto quanto fatos concretos); a isso adicionou-se um fluxo crescente de recursos aplicados na Bolsa oriundo dos efeitos das várias medidas listadas acima. ${ }^{13}$

Não deixa de ser revelador que o movimento de alta, embora muito expressivo, teve fôlego curto. No caso da Bovespa a sua reversão ocorreu já em agosto, quando o índice Bovespa atingiu o pico de 597 (226 em janeiro), declinando em seguida para 510 em dezembro, enquanto o volume mensal de transações recuava acentuadamente, só voltando a se recuperar no segundo semestre de $1970 .{ }^{14}$ No fundo, a experiência de 1969 não passou de uma amostra do que ainda estava por vir, mas a maturação plena da bolha especulativa dependia de novos ingredientes.

\section{A BOLHA ESPECULATIVA E SEU COLAPSO}

Durante aproximadamente um ano observou-se um melancólico marasmo no mercado de ações. Por exemplo, ao longo do primeiro semestre de 1970 o IBV oscilou em torno de 800 , atingindo o seu menor valor no mês de junho, enquanto o volume mensal de transações foi substancialmente inferior ao registrado nos momentos mais intensos do boom. Este não ensejara nenhuma autocrítica ou mudança de perspectiva. A política econômica continuaria a jogar suas fichas numa rápida consolidação do mercado

13 Diversos relatos contemporâneos destacavam inclusive o possível papel desempenhado por capitais provenientes do exterior - ver, por exemplo, as declarações do presidente da BVRJ em Visão, 29/08/69.

14 Como sempre, é possível apontar fatores imediatos que teriam interrompido o boom: a decisão de proibir a reavaliação do ativo fixo das empresas portuárias, afetando uma blue chip (a Cia. Docas de Santos) e despertando o temor de que viesse a ser estendida a outros setores empresariais; e a venda maciça de ações ordinárias da Petrobrás (outra blue chip) realizada por Estados e Municípios, baixando a sua cotação. Ver análises contemporâneas em Banas Financeiro, 1970/71; ANPES, Boletim Trimestral, 1969 e 1970; Visão, 15/08/69 e 29/08/69. 
de capitais a partir da dinamização das transações na Bolsa. ${ }^{15}$ De fato, o conjunto anterior de medidas é inteiramente preservado, o apoio oficial ao mercado de capitais é sempre reiterado e a estagnação das Bolsas constitui motivo de séria preocupação - o que se traduziu em novos estímulos visando à sua reativação. Cabe mencionar as seguintes medidas, todas de 1970:

- a regulamentação dos fundos mútuos de investimento, estipulando uma aplicação mínima de 60\% dos recursos em ações (Resolução nº 145, de 14.04.1970); posteriormente foi limitada em 15\% dos recursos as aplicaçôes em letras de câmbio, ademais com prazo mínimo de dois anos (Resolução no 164 , de 24.11.1970);

- a permissão aos Fundos 157 para aplicarem dois terços dos recursos em operações na Bolsa (Resolução $\mathrm{n}^{\circ} 146$, de 08.05.1970); a extensão do benefício do Decreto-Lei $\mathrm{n}^{\circ} 157$ aos contribuintes atingidos apenas pelo imposto de renda na fonte (Portaria GB-95, de 16.04.1970, do Ministério da Fazenda, instituindo o "cheque de poupança"); a mudança no esquema de resgate das quotas dos Fundos 157, passando de integral após dois anos para parcelado em $30 \%$ no $2^{\circ}$ ano, $50 \%$ no $3^{\circ}$ ano e o restante no $4^{\circ}$ ano (Decreto-Lei no 1.109 , de 26.06.1970).

A injeção de recursos na Bolsa com origem nos fundos de investimento foi considerável. $\mathrm{O}$ valor patrimonial conjunto dos principais fundos mútuos cresceu de forma impressionante: 60 milhões de cruzeiros em 1967, 135 milhões em 1968, 556 milhões em 1969, 1.048 milhões em 1970 e 3.167 milhões em 1971; no ano de 1971 o patrimônio total dos 121 fundos mútuos registrados totalizou 4.738 milhões de cruzeiros (para efeito de comparação, tenha-se em conta que em 1971 o saldo de letras de câmbio atingiu 15.177 milhões e o de depósitos a prazo 8.461 milhões), enquanto os Fundos 157 lograram mobilizar 624 milhões de cruzeiros em 1970 e 1.381 milhões em 1971 (com um correspondente crescimento das transações com ações do mercado secundário). ${ }^{16}$

Essa evolução coincidiu com a plena explicitação do ciclo expansivo. De fato, até o final de 1969 a recuperação ainda não era percebida como um desvio para cima em relação à média histórica de crescimento. Predominava, então, a modéstia nos círculos oficiais - veja-se o tom do discurso oficial presente no PED - Programa Estratégico de Desenvolvimento (1968) e no documento subseqüiente ao AI-5 O Programa Estratégico

15 Alguns analistas da grande imprensa perceberam com notável lucidez o alcance do processo iniciado em 1969. Eis um exemplo: "O Governo poderia dar-se por satisfeito: conseguin dinamizar realmente o mercado de açôes. Entretanto, uma análise fria leva a questionar a excelência desses resultados... as autoridades poderão ver-se na obrigação de intervir de um modo mais direto nas bolsas de valores. Mas uma intervenção intempestiva poderá desacreditar por muitos anos um mercado de açôes ainda incipiente e será severamente julgado pelos pequenos inversores, mais uma vez prejudicados.” Cf. 'Na bolsa, o risco da desilusão', em Visão, 15/08/69.

16 Ver Relatório do Banco Central, 1971 e Anuário da BVSP, 1971. 
e os novos instrumentos de politica econômica (Brasil, 1969). Mas, desde o início de 1970 uma revisão das estatísticas do desempenho da economia resultou na descoberta de que o crescimento na verdade vinha se fazendo num ritmo inesperadamente alto. E não só isso: o governo Médici trouxe como novidade em relação aos dois governos anteriores uma retórica grandiloqüente, assumindo de forma enfática uma meta de crescimento ambiciosa (10\% a.a.), expressão sintética do projeto Brasil Grande Potência (o status almejado e projetado para o ano 2000). Tinha início, assim, o "milagre" brasileiro. Com a política econômica manifestando irrestrita simpatia no que se refere ao papel da Bolsa de Valores, isso naturalmente criava um ambiente por demais propício ao surgimento de uma bolha especulativa. ${ }^{17}$

Esta teria sido deflagrada pelo efeito gerado a partir do anúncio de aumento de capital do Banco do Brasil (subscrição com direito a bonificação, na base de um para um) em meados de 1970, ganhando impulso com a divulgação no final do ano do Plano Siderúrgico Nacional (um dos "projetos impacto" da administração Médici). Assim, no decorrer do segundo semestre de 1970, parafraseando Keynes, as tênues "borbulhas" que vinham se formando havia um ano se transformaram em uma "corrente firme" da especulação: o volume de negócios (Bovespa e BVRJ) aumentou expressivamente, atingindo um valor médio mensal ao redor de 700 milhões de cruzeiros no trimestre setembro/novembro e o nível recorde de 950 milhões de cruzeiros em dezembro; o IBV (BVRJ) evoluiu aos saltos de um índice 790 (junho) para 1.252 (setembro) e 1.570 (dezembro), alcançando um máximo de 1.727 no último dia de operações do ano.

Ao longo do primeiro semestre de 1971 a "corrente firme" desaguaria em um verdadeiro "turbilhão" especulativo. Os números são eloqüientes. Em um único mês (março) o movimento, em valor real, registrado na Bovespa foi equivalente a quase $80 \%$ do movimento anual de 1969; em abril o fenômeno se repetiu; em maio o movimento foi 40\% superior ao de 1969 (e equivalente a 80\% do movimento anual de 1970); em junho o fenômeno se repetiu. Enquanto o movimento acumulado de março a junho registrado na BVRJ ultrapassou o movimento total de 1969 e 1970 somados. $\mathrm{Na}$ Bovespa, o crescimento foi ainda maior (65\% superior). O comportamento dos

17 Um documento oficial, resenhando a performance da economia em 1970, alinharia entre os êxitos alcançados a "excepcional vitalidade" das Bolsas (Exposição de motivos conjunta dos ministros da Fazenda e do Planejamento ao presidente da República, reproduzido em O Estado de São Paulo, 7 01-71). Delfim Netto, em nota divulgada durante a reunião anual do FMI-BIRD, tecia um discurso autocongratulatório e exultante: "A criação de incentivos fiscais para investimentos em sociedades de capital aberto resultou numa extraordinária expansão do mercado de capitais. A bolsa do Rio de Janeiro é hoje uma das cinco maiores do mundo...” (O Estado de São Paulo, 22-09-70). E Reis Velloso, diante da reativação da Bolsa, anteciparia: "Este ano o modelo industrial brasileiro deverá ganhar seus contornos fundamentais. Aproveitando o boom das Bolsas de Valores, pretendemos modernizar as estruturas empresariais, fazendo com que as empresas reduzam seu grau de endividamento em capital de movimento e fixo, pela expansão do capital acionário... Queremos a expansão do mercado primário de ações e, conseqüentemente, do secundário."(Correio da Manhã, 25.01.71). 
índices de preços reflete fielmente toda a "exuberância" do processo: o índice Bovespa evoluiu de um nível próximo a 850 (dezembro de 1970) para um máximo de 2.573 (em meados de junho de 1971); o IBV, tendo alcançado 1.727 no final de 1970, escalaria o pico de 5.236 (junho de 1971). ${ }^{18}$

A altíssima rentabilidade a curto prazo propiciada pela Bolsa - inteiramente apoiada pela política econômica, não revelando nenhum receio quanto aos riscos inerentes a um boom tão intenso - não deixaria de seduzir o pequeno investidor. Como é usual, a classe média afluiria em grande número quando a bolha já se aproximava de seu limite - desfazendo-se de bens tangíveis (automóvel, apartamento) ou mesmo endividando-se junto à rede bancária, na certeza de colher lucros mais que compensadores. A propósito, observe-se que os créditos a particulares concedidos pelos bancos comerciais (exceto o Banco do Brasil) representaram cerca de 19,7\% do crédito bancário ao setor privado em 1971 (em comparação com 18,7\% em 1970). ${ }^{19}$

Há indicações de que o vulto do frenesi especulativo na Bolsa gerou problemas localizados decorrentes de um desvio de recursos. Tal foi o caso das financeiras às voltas com dificuldades para colocar no mercado suas letras de câmbio, suscitando pleitos de esquemas de refinanciamento para absorver excedentes ocasionais, surgimento de ágio sobre as taxas de juros das letras de câmbio e sobre o CDC (Crédito Direto ao Consumidor) - que se elevam de 1,9 para 3,0\% a.m. e de 2,9 para 4,0\% a.m., respectivamente -, aquisições de letras de câmbio pelas próprias instituições conglomeradas como forma de apoio à financeira associada. Uma observação atenta do comportamento dos empréstimos mediante aceite cambial no primeiro semestre de 1971 (quando cresceu vigorosos $40,5 \%$ ) revela uma forte concentração das operações no mês de janeiro, seguido de uma expansão bastante modesta de fevereiro a junho (crescimento acumulado de 14,5\%; em valor absoluto, $21 \%$ inferior ao realizado apenas no mês de janeiro). É sintomático que o CMN (Conselho Monetário Nacional) tenha autorizado (em 20.05.1971 - clímax da bolha) o uso de recursos do PIS, via Finame, num esquema de sustentação das financeiras, enquanto a Resolução no 188 permitiu a compra (em caráter emergencial: até 31.07.1971) de letras de câmbio com prazo inferior a

18 Atente-se para a evolução das cotações de algumas blue chip, de janeiro a meados de maio: Vale PP - 18,27 para 35,60; Belgo - 4,27 para 12,60; Ferro Brasileiro 0P - 3,27 para 6,20; White Martins 0P - 3,88 para 10,00; Petrobrás PP - 2,68 para 14,00; Ind. Villares PP-A - 7,65 para 16,00. As ações das empresas novas foram as preferidas pelos investidores; o caso mais espetacular terá sido a Sudeste: de 1,20 na fase de pré-lançamento em janeiro, atingiu a cotação de 15,50 em maio. Cf. Visão, 7-06-71.

19 Ver Relatório do Banco Central, 1971. A participação da classe média, vítima obrigatória do colapso da bolha, não apresenta novidade. Keynes (1983), descrevendo a "luta de esperteza" que caracteriza a especulação, e Hilferding (1985), referindo-se ao típico comportamento reflexo que leva o ingênuo pequeno investidor a desempenhar um papel essencial na realização dos "lucros diferenciais" do grande especulador profissional, anteciparam esse aspecto das bolhas especulativas. A novidade do caso brasileiro foi a explícita participação da política econômica na deflagração do processo. 
24 meses pelos fundos mútuos de investimento (revogando as restrições introduzidas em novembro de 1970). ${ }^{20}$

Nos momentos finais da aventura da Bolsa, Delfim Netto resumiria a rationale da política de mercado de capitais: "o primeiro passo foi criar o mercado. Sem a criação desse mercado, seria inutil tentar induzir as empresas a abrirem o seu capital. Uma vez formado o mercado, criou-se a idéia de que elas poderiam abrir o seu capital." ${ }^{21} \mathrm{O}$ mercado sem dúvida havia surgido: a Bolsa (SP e RJ) atingira a quinta posição no ranking mundial, evoluindo para a terceira posição durante o auge de 1971 (na avaliação do Times de Londres). E um surto de lançamentos novos de ações chegou a ocorrer. Visando acelerar o processo, foi introduzida nova modificação na legislação (Resolução no176, de 09.03.1971): o CCA teria sua renovação a cada dois anos sempre que a empresa aumentasse em 10\% o grau de abertura seja através de ações ordinárias seja de preferenciais (até então era obrigatória a emissão de ações ordinárias, diluindo o controle). Em 1971, o número de lançamentos novos cresceu expressivamente, atingindo a marca de 254 (contra 83 em 1970). No entanto, registram-se freqüentes casos de ágios acima de 50\% (e não raramente de 100 a 200\%), com predominância de emissão de preferenciais. É bem possível que essa fase tenha refletido muito mais um viés especulativo (perspectiva de um altíssimo "lucro do lançador", repartido entre a S.A. e a instituição promotora do lançamento) do que sinalizado um amadurecimento do processo de democratização do capital. ${ }^{22}$

É interessante notar que durante todo o primeiro semestre de 1971 o volume de lançamentos novos atingiu a cifra de 322 milhões de cruzeiros; em julho, agosto e setembro os registros de emissões totalizaram 263, 461 e 527 milhões, respectivamente (com destaque para vultosos lançamentos de estatais como a CESP e a CEMIG). ${ }^{23}$ A intensificação dos lançamentos coincidiu com a reversão do boom; no fím de 1971 avolumavam-se queixas de um excesso de papéis (motivado pelas subscrições e bonificações), fator de depressão do mercado secundário.

Com efeito, após atingir um ponto máximo em meados de junho o movimento especulativo arrefeceu: os índices Bovespa e IBV registrariam contínuas quedas a partir

20 O presidente da Acrefi (Associação Nacional das Instituições de Crédito, Financiamento e Investimento) qualificaria de "histeria coletiva" o movimento da Bolsa e apontaria as seqüelas negativas sobre as financeiras. Discretamente o setor pressionava as autoridades para que introduzissem a taxação de ganhos de capital, levando Delfim Netto a manifestar-se explicitamente: "O Governo não está examinando qualquer medida para taxar os lucros dos investidores em Bolsa de Valores." Ver Carta Mensal APEC 15/05/71, p. 17 e Banas, 24/05/71. Também o mercado imobiliário viu-se negativamente afetado: o presidente do Sindicato da Guanabara, por exemplo, afirmaria taxativamente que "a compra de imóveis para renda ou para simples especulação desapareceu” (Visão, 7/06/71). Ver também Carta Mensal APEC, $15 / 09 / 71$, p. 2 e $15 / 10 / 71$, p. $2-4$

21 Banas, 16/08/71.

22 Ver Relatório do Banco Central, 1971 e Anuário da BVSP, 1971.

23 Ver Conjuntura Econômica, fev. 1972. 
de julho. Mas, ao invés de um crash súbito, o que se verificou foi uma lenta agonia, com as cotações diminuindo persistentemente em um processo contínuo, entrecortado por ligeiras (e ilusórias) ameaças de recuperação (por exemplo, em dezembro de 1971 e em agosto-setembro de 1972).

O esgotamento do boom foi precedido de algumas medidas de controle:

- redução para 30\% da margem permitida para operações em Bolsa por parte dos fundos fiscais (Resolução no185, de 20.05.1971);

- aumento da margem em dinheiro, de 20 para 40\%, no mercado a termo (Resoluçôes no 14 , de 29.03.1971, e no 15, de 14.06.1971, do Conselho de Administração da BVRJ). ${ }^{24}$

Qualquer que tenha sido o seu impacto, é duvidoso que tais medidas tenham causado a reversão do boom; o mercado a termo representou apenas 15\% das transações no início do auge, caindo em seguida para 6 ou 7\%; o papel dos fundos foi muito mais importante na deflagração do processo, agora sendo suplantados pela entrada em grande número dos investidores individuais. Mesmo que o crescimento da bolha pudesse despertar apreensão nas autoridades, é plausível supor que sua atitude seria, no essencial, a de aguardar passivamente o reajustamento automático a ser produzido pela própria dinâmica do mercado. Conforme observou Galbraith a propósito do crash de 1929 nos Estados Unidos:

"Uma bolba pode ser facilmente furada. Mas picá-la com uma agulha, de forma que ela diminua gradativamente, é uma tarefa bastante delicada... A verdadeira escolba era entre um colapso imediato e deliberadamente planejado e um desastre mais sério depois. Alguém, com certeza, seria acusado pelo colapso final quando este viesse. Não havia qualquer divida quanto a quem seria acusado, se o boom fosse deliberadamente derrubado. 25

No caso brasileiro isso era tão mais verdadeiro quanto a orientação da política de mercado de capitais fora diretamente responsável pela formação da bolha. Um sinal claro dessa postura foi a terminante recusa em tributar ganhos de capital.

O volume anual de transações nas Bolsas cresceu mais de quatro vezes em 1971 (em valor real), para declinar fortemente de 1972 a 1974. Na esteira da estagnação dos

24 Também se tentou coibir práticas inescrupulosas dos agentes do mercado. Um exemplo foi a proibição imposta às corretoras de venderem ações que ainda não houvessem recebido. Referências ao caótico ambiente operacional que caracterizou essa conjuntura encontram-se em CVM (1979); Carta Mensal APEC, 15/09/71 (A.Wald: Novos Rumos para o Mercado de Capitais); Bueno (1981).

25 Galbraith (1972, p. 61). 
negócios em Bolsa, os novos lançamentos - objetivo último da política de mercado de capitais - também declinaram acentuadamente, retornando à posição anterior de irrelevância para o financiamento empresarial.

\section{EPÍLOGO: CONTINUIDADE E IMPOTÊNCIA DA POLÍTICA DE MERCA- DO DE CAPITAIS}

À medida que a bolha ia desinflando, as autoridades econômicas prosseguiram renovando sua crença na importância do mercado de capitais - como se os episódios de 1970-1971 configurassem um mero acidente de percurso. ${ }^{26}$ Igualmente foram ampliados os incentivos à formação de poupança pessoal voluntária e à recuperação da Bolsa. Assim, já em novembro de 1971 eram modificadas novamente as margens obrigatórias do mercado a termo, passando de $40 \%$ em dinheiro e $20 \%$ em títulos para $15 \%$ em dinheiro e $45 \%$ em títulos. Em conseqüência, o mercado a termo saltaria de 5 para 20\% do movimento diário na BVRJ. Os Fundos 157, por sua vez, experimentariam sucessivas alterações: elevação para $80 \%$ da parcela liberada para aplicação em Bolsa (Resolução n²18, de 28.03.1972); ampliação de 12 para 24\% da margem de dedução do imposto de renda devido (Decreto-Lei n ${ }^{\circ} 1.214$ ); extinção da figura da “empresa-157" (Resolução n²21, de 10.05.1972). Os fundos mútuos de investimento tiveram reduzida de 40 para $20 \%$ a margem permitida para aplicação em títulos de renda fixa (Resolução n⿳219, de 20.04.1972). Instituiu-se o FUMCAP (Fundo de Desenvolvimento do Mercado de Capitais), constituído de repasses do BNDE (Banco Nacional de Desenvolvimento Econômico) e da CEF aos bancos de investimento para lastrear operações no mercado primário (Decreto-Lei n69.554, de 18.11.1971; Resolução n²13, de 02.03.1972; Circular no199, de 25.01.1973). Esse programa experimentou sucessivos atrasos e somente no fim de 1973 efetivaria uma primeira operação, de reduzido valor. O Decreto-Lei no1.259, de 19.02.1973, autorizou a CEF a atuar nos mercados primário e secundário de ações; esta, não obstante, terminou revelando desinteresse em fazê-lo. (Em 1972, recursos do PIS haviam sido alocados na Bolsa - primeiro, nas ações que compõem os índices da Bolsa visando reverter expectativas baixistas, em seguida nas ações do chamado "bloco intermediário"). ${ }^{27}$

26 Assim, Delfim Netto explicaria "que a bolsa não é jogo, é investimento a longo prazo... ao lado de dezenas de milhares de especuladores devem existir milhões de investidores... Com a alta do ano passado, invertemos as coisas. Tivemos milhares de investidores e milhões de especuladores." (Folha de São Paulo, 16/04/72). Ele renovaria a crença ao observar que, olhando da perspectiva correta (o longo prazo), "as aplicaçôes do mercado de capitais são altamente rentáveis e constituem um fator extremamente importante para a construção de uma sociedade aberta no Brasil”. (Banas, 16/08/71). Para uma avaliação crítica desse tipo de perspectiva ver as observações de Keynes (1983).

27 Ver Banas, Brasil Financeiro 1973-1974, p. 125; Mundo Econômico, dez.1972, p.40; Visão, 24/04/72. 
Os frutos dessa linha de ação nunca foram além de passageiros relançamentos do mercado. Prosseguindo o estado de agonia da Bolsa, as sugestões de medidas tenderam a se multiplicar. Exemplos dessa busca de solução: fomento de novos investidores institucionais (via criação de fundos de pensão ou atração das companhias seguradoras); instituição de um órgão similar à SEC norte-americana; modificação na legislação das sociedades anônimas; criação de uma carteira de redesconto dos fundos mútuos de investimento com recursos do PIS; permissão para a entrada de capital estrangeiro na Bolsa etc. Com maior ou menor intensidade, essas propostas estiveram em circulação durante 1972-1973, sem chegar a prosperar. Delfim Netto manifestaria simpatia pela idéia de aperfeiçoar a legislação de capital aberto - visando "proteger melhor a minoria acionária, o pequeno acionista", de forma a "atrair um número cada vez maior de investidores”, mas repudiaria a proposta de capital estrangeiro na Bolsa, dados os riscos de desnacionalização e de sujeição aos humores de um eventual hot money e suas seqüelas negativas. ${ }^{28}$ Quanto à necessidade de uma presença importante de investidores institucionais, um entusiasta do mercado de capitais observou à distância: "70 e 71 no mercado não teriam acontecido se existisse um institucional mais forte, para equilibrá-lo. "29 Contudo, bolhas especulativas ocorreram em mercados maduros, com ampla participação dos institucionais - como realçado por Shiller (2000).

De concreto, um amplo conjunto de incentivos fiscais ganharia forma no Decreto-Lei $\mathrm{n}^{\mathrm{O}} 1.283$, de 20.08.1973 (à época qualificado de Nova Lei do Mercado de Capitais, dada a sua abrangência). Dentre as inovações introduzidas, destacam-se:

- estímulo à distribuição de dividendos: isenção de tributação sobre o valor de dividendos distribuídos em montante superior a 25\% do lucro líquido;

- permissão para abater da renda bruta o valor dos dividendos reaplicados na subscrição de açốes;

- redução de 15 para $10 \%$ da alíquota do imposto de renda na fonte incidente sobre os dividendos;

- desestímulo à prática de conceder bonificações em ações no lugar de bonificações em dinheiro, o que era devido à ausência de tributação sobre a incorporação de reservas (esta foi tornada menos atrativa com a exclusão das correções monetárias do ativo imobilizado e do capital de giro quando do cálculo do excesso de reservas);

28 Ver Folba de São Paulo, 16/04/72 e 8/06/72. A Nova Lei das S.A. e a instituição da CVM viriam no governo seguinte, em 1976. Sobre esse desdobramento da política de mercado de capitais, ver as observações de Lessa (1998). Já a permissão para a livre atuação do capital estrangeiro na Bolsa teria de esperar até o advento da era neoliberal nos anos 90.

29 Roberto Teixeira da Costa, citado em Almeida (1984, p. 34). 
- permissão para reduzir até $30 \%$ da renda bruta as aplicações em fundos de investimento mantidas por três anos, assim como as debêntures convertidas em ações (e percentuais menores no caso de aplicações em debêntures simples e conversíveis). ${ }^{30}$

Não obstante a reafirmação da política de incentivo à posse de ações pelo poupador individual - a qual prosseguiu com novos desdobramentos durante o governo Geisel com sua diretriz de fortalecimento do capital privado nacional ${ }^{31}$ - os resultados foram pífios. O volume anual de transações na Bolsa (SP e RJ) declinou 40,1\% em 1972, 14,0\% em 1973 e 41,0\% em 1974 (e uma recuperação aparente em 1975 seria seguida por nova queda e estagnação no triênio 1976-1978). Somente em 1976 o índice Bovespa voltaria a atingir as marcas registradas durante o pico especulativo (não representando nenhuma recuperação, dada a inflação acumulada no período). Enquanto isso, o mercado primário praticamente desaparecia: os bancos de investimento terminaram abandonando a área de operações de underwriting_(uma de suas funções originais) e o próprio Banco Central viu-se levado a proibir novos lançamentos, na ânsia de evitar uma queda ainda maior das cotações no mercado secundário. Sem dúvida, após a bolha o mercado de capitais atravessou a sua "década perdida". 32

\section{CONSIDERAÇOEES FINAIS}

A magnitude alcançada pela bolha especulativa em um curto período e o prolongado estado de prostração que se seguiu explicitam os riscos que a política econômica aceitou correr a partir de 1968 na busca de uma rápida maturação do mercado de capitais. Admitindo a conveniência de lograr desenvolver esse mercado, observou-se o surgimento de uma crônica crise de confiança da parte dos investidores, tornando ineficaz a ação da política econômica e diferindo para um futuro incerto aquela meta perseguida desde a reforma de $1965 .^{33}$

Mas se a Bolsa permaneceu prostrada, a especulação seguiu o seu curso, explorando com sucesso outras alternativas de ganho. De início, isso se refletiu na persistente e significativa alta de preços da terra agrícola e dos terrenos e imóveis urbanos. ${ }^{34} \mathrm{Em}$ meio à desaceleração cíclica da segunda metade da década a especulação financeira com títulos a juros (então designada "ciranda financeira") tornou-se uma importante

30 Ver Conjuntura Econômica, set.1973 e Relatório do Banco Central, 1973.

31 Ver a respeito Lessa (1998, p. 224-242).

32 Apenas em 1983 - em plena depressão - uma nova bolha seria observada, com o índice Bovespa exibindo uma espantosa valorização real da ordem de $176 \%$. Ver Rioli (1984).

33 Ver a avaliação feita por observadores insuspeitos: CVM (1979, p.98).

34 Em cruzeiros de 1975 observa-se uma alta de 16\% em 1972, 59\% em 1973, 32\% em 1974 e 22\% em 1975 nos preços da terra agrícola. Ver Sayad (1978). 
fronteira de valorização dos capitais. É plausível supor que a existência dessa verdadeira "fronteira aberta" da especulação tenha tido um peso maior que o fator crise de confiança para manter estagnada a atividade bursátil.

O colapso da Bolsa não engendrou nenhum efeito riqueza. Ao contrário, em 19721973 o ciclo expansivo da economia atingiu um estado de sobreexcitação. A ativação da Bolsa foi irrelevante na gestação e sustentação do "milagre". Além disso, a sua reversão não obstou a continuidade da expansão, apoiada que estava em outra dinâmica. Isso suscita uma breve menção àquela que é a mais certeira crítica à política de mercado de capitais do regime militar: o seu caráter contraditório em relação à dinâmica de crescimento baseada na expansão - alicerçada no endividamento pessoal - do consumo (de duráveis). Caso efetivamente tivessem se materializado as expectativas em relação ao comportamento do pequeno poupador (adiando o consumo, isto é, evitando o endividamento), o vigoroso crescimento observado durante o "milagre" seria comprometido. ${ }^{35}$

\section{REFERÊNCIAS BIBLIOGRÁFICAS}

Almeida, J. S. G. As reformas financeiras de 1964-65: objetivos, rumos e desvios. IEI/UFRJ, 1984. (Texto para discussão n. 59).

BRASIL. M. P. C. G. - Ministério do Planejamento e Coordenação Geral. O Programa Estratégico e os novos instrumentos de política econômica, Brasília, DF, 1969.

Bueno, R. Escândalos financeiros no Brasil. Petrópolis: Editora Vozes, 1981.

Comissão de Valores Mobiliários - CVM. Sistema de Intermediação de Valores Mobiliários. Rio de Janeiro: CVM, 1979.

Fishlow, A. Algumas reflexões sobre a política econômica brasileira após 1964. Estudos CEBRAP n. 7, jan./mar. 1974.

Galbraith, J. K. O colapso da Bolsa, 1929. Rio de Janeiro: Editora Expressão e Cultura, 1972.

Hilferding, R. O capital financeiro. São Paulo: Nova Cultura, 1985.

Keynes, J. M. Teoria geral do emprego, do juro e do dinheiro. São Paulo: Abril Cultural, 1983.

Lessa, C. A estratégia de desenvolvimento 1974-1976: sonho e fracasso. Campinas: UNICAMP/ IE, 1988.

Resende, A. L. A política brasileira de estabilização: 1963-68. Pesquisa e Planejamento Econômico, v. 12, n. 3, dez. 1982.

35 Ver Lessa (1998) para o desenvolvimento desse argumento, bem como para sugestivas reflexões adicionais, aqui tangenciadas. 
Rioli, W. A. Mercado de ações na economia brasileira. Tibiriçá n. 21, jul./dez. 1984.

Sayad, J. Preço da terra e mercados financeiros. IPE/USP, jun. 1978. Mimeografado.

Shiller, R. J. Exuberância irracional. São Paulo: Makron Books, 2000.

Silva, A. M. Intermediação financeira. FIPE/USP, 1980. Mimeografado.

Sochaczewski, A. C. Financial and economic development of Brazil, 1953-1968. 1980. Tese (Doutorado). London School of Economics and Political Science.

Wanderley, C. A.; Pimentel, R. B. O caminho brasileiro dos bancos de investimento. Cadernos Halles, n. 5, 1970. 


\section{APÊNDICE}

TABELA 1 - EVOLUÇÃO GERAL DE NEGÓCIOS COM AÇÕES DE BANCOS E COMPANHIAS - EM CR \$ MILHÕES - A PREÇOS DE SET/1971

\begin{tabular}{|c|c|c|c|c|c|c|}
\hline & \multicolumn{2}{|c|}{1969} & \multicolumn{2}{|c|}{1970} & \multicolumn{2}{|c|}{1971} \\
\hline & Bovespa & BVRJ & Bovespa & BVRJ & Bovespa & BVRJ \\
\hline $\mathrm{J}$ & 43 & 79 & 82 & 631 & 523 & 929 \\
\hline $\mathrm{F}$ & 49 & 75 & 88 & 218 & 525 & 696 \\
\hline M & 53 & 105 & 126 & 261 & 947 & 1.357 \\
\hline A & 61 & 109 & 94 & 224 & 912 & 1.374 \\
\hline M & 99 & 180 & 94 & 186 & 1.664 & 2.481 \\
\hline J & 108 & 183 & 67 & 150 & 1.763 & 1.978 \\
\hline$J$ & 131 & 320 & 138 & 291 & 1.010 & 1.191 \\
\hline A & 219 & 373 & 174 & 342 & 852 & 1.089 \\
\hline$S$ & 138 & 279 & 245 & 429 & 854 & 1.011 \\
\hline 0 & 134 & 348 & 251 & 421 & 901 & 863 \\
\hline $\mathrm{N}$ & 91 & 189 & 229 & 453 & 598 & 793 \\
\hline$D$ & 106 & 190 & 387 & 563 & 1.037 & 1.013 \\
\hline $\mathrm{T}$ & 1.232 & 2430 & 1.975 & 4.169 & 11.586 & 14.775 \\
\hline
\end{tabular}

Obs. : Os dados para a BVRJ referem-se ao mercado global.

Fonte: Anuário da Bolsa de Valores de São Paulo, 1971.

TABELA 2 - VOLUME ANUAL DE TRANSAÇÕES NAS BOLSAS DE VALORES DO RIO DE JANEIRO E SÃO PAULO - AÇÕES - 1961 A 1978 - EM CRUZEIROS CORRENTES E EM CRUZEIROS REAIS (PREÇOS DE 1978)

\begin{tabular}{lccrrr}
\hline & $\begin{array}{c}\text { Cr\$ milhões } \\
\text { correntes }\end{array}$ & $\begin{array}{c}\text { Cr\$ milhões } \\
\text { de 1978 }\end{array}$ & & $\begin{array}{c}\text { Cr\$ milhões } \\
\text { correntes }\end{array}$ & $\begin{array}{c}\text { Cr\$ milhões } \\
\text { de 1978 }\end{array}$ \\
\hline 1961 & 12.4 & 2.122 .8 & 1970 & 4.558 .0 & 34.011 .3 \\
1962 & 34.1 & 3.886 .5 & 1971 & 25.553 .0 & 156.901 .1 \\
1963 & 86.3 & 5.587 .7 & 1972 & 18.005 .0 & 93.919 .5 \\
1964 & 111.5 & 3.981 .5 & 1973 & 17.852 .0 & 80.722 .1 \\
1965 & 206.5 & 4.799 .1 & 1974 & 13.582 .0 & 47.579 .9 \\
1966 & 151.0 & 2.487 .7 & 1975 & 26.677 .0 & 73.131 .0 \\
1967 & 269.0 & 3.497 .0 & 1976 & 28.061 .0 & 54.804 .6 \\
1968 & 416.0 & 4.409 .1 & 1977 & 37.696 .0 & 52.359 .1 \\
1969 & 2.461 .0 & 21.898 .9 & 1978 & 52.960 .0 & 52.960 .0 \\
\hline
\end{tabular}

Fonte: Comissão de Valores Mobiliários, 1979. 
TABELA 3 - MOVIMENTO DE AÇÕES NAS BOLSAS DE VALORES DO RIO DE JANEIRO E SATO PAULO. EM CR\$ MIL - VALORES NOMINAIS

\begin{tabular}{lrrr}
\hline & BVRJ & BVSP & TOTAL \\
\hline 1963 & 58.155 & 27.809 & 85.964 \\
1964 & 76.858 & 36.056 & 112.914 \\
1965 & 124.290 & 82.000 & 206.290 \\
1966 & 100.294 & 51.387 & 151.681 \\
1967 & 174.318 & 94.192 & 268.510 \\
1968 & 248.623 & 162.607 & 411.230 \\
1969 & 1.403 .390 & 847.329 & 2.250 .119 \\
\hline
\end{tabular}

Fonte: ANPES, Boletim Trimestral, 1969 e 1970.

TABELA 4 - EVOLUÇÃO DO ÍNDICE BOVESPA (BVSP) - VALOR MÉDIO MENSAL

\begin{tabular}{lrrrrrr}
\hline & \multicolumn{2}{c}{1971} & & \multicolumn{3}{c}{1972} \\
\cline { 2 - 3 } \cline { 5 - 6 } & Índice & $\Delta \%$ & Índice & \multicolumn{1}{c}{$\Delta \%$} \\
\hline $\mathrm{J}$ & 991.1 & 24.70 & & 1.743 .0 & -0.31 \\
$\mathrm{~F}$ & 1.094 .4 & 10.42 & & 1.664 .7 & -4.49 \\
$\mathrm{M}$ & 1.162 .5 & 6.22 & & 1.534 .9 & -7.79 \\
$\mathrm{~A}$ & 1.381 .0 & 18.80 & & 1.381 .3 & -10.01 \\
$\mathrm{M}$ & 1.791 .0 & 29.69 & & 1.409 .5 & 2.04 \\
$\mathrm{j} \S$ & 2.427 .1 & 35.52 & & 1.357 .6 & $-3,68$ \\
$\mathrm{~J}$ & 2.262 .9 & -6.77 & & 1.105 .0 & -18.61 \\
$\mathrm{~A}$ & 2.090 .9 & -7.60 & & 1.139 .7 & 3.14 \\
$\mathrm{~S}$ & 2.023 .9 & -3.21 & & 1.239 .2 & 8.73 \\
$\mathrm{O}$ & 1.874 .2 & -7.40 & & 1.085 .7 & -12.39 \\
$\mathrm{~N}$ & 1.692 .2 & -9.71 & & 1.012 .5 & -6.74 \\
$\mathrm{D}$ & 1.748 .5 & 3.33 & & 1.015 .8 & 0.33 \\
\hline
\end{tabular}

$\$$ Valor máximo em 14 de junho de $1971: 2.573 .9$

Obs. : O índice Bovespa é um índice de lucratividade das ações mais negociadas na BVSP. É calculado desde 2 de janeiro de 1968, ocasião em que seu valor equivalia a 100.

Fonte: Anuário da BVSP, 1971 e 1972. 
TABELA 5 - EVOLUÇÃO DO IBV (BVRJ) - VALOR MÉDIO MENSAL

\begin{tabular}{|c|c|c|c|c|}
\hline \multicolumn{3}{|c|}{1971} & \multicolumn{2}{|c|}{1972} \\
\hline & Índice & $\Delta \%$ & Índice & $\Delta \%$ \\
\hline $\mathrm{J}$ & 2.020 .3 & 23.2 & 3.494 .7 & -1.2 \\
\hline $\mathrm{F}$ & 2.176 .7 & 7.7 & 3.396 .7 & -2.8 \\
\hline$M$ & 2.411 .6 & 10.8 & 3.196 .4 & -5.9 \\
\hline$A$ & 2.849 .7 & 18.2 & 2.869 .0 & -10.3 \\
\hline$M$ & 3.694 .2 & 29.6 & 2.809 .7 & -2.1 \\
\hline j§ & 4.908 .1 & 32.9 & 2.629 .4 & -6.4 \\
\hline $\mathrm{J}$ & 4.667 .8 & -4.9 & 2.001 .9 & -23.9 \\
\hline$A$ & 4.381 .8 & -6.1 & 2.018 .8 & 0.8 \\
\hline$S$ & 4.183 .8 & -4.4 & 2.368 .0 & 17.3 \\
\hline 0 & 3.797 .3 & -9.3 & 2.104 .2 & -11.1 \\
\hline $\mathrm{N}$ & 3.375 .6 & -11.1 & 1.985 .6 & -5.7 \\
\hline D & 3.536 .1 & 4.8 & 1.910 .3 & -3.8 \\
\hline
\end{tabular}

\$ Valor máximo em 14 de junho de 1971 : 5.236 .3

Fonte: Anuário da BVSP, 1972. 